\title{
The expression of wild-type pendrin (SLC26A4) in human embryonic kidney (HEK 293 Phoenix) cells leads to the activation of cationic currents
}

\author{
Silvia Dossena ${ }^{1}$, Antonella Maccagni ${ }^{1}$, Valeria Vezzoli ${ }^{1}$, Claudia Bazzini $^{1}$, Maria Lisa Garavaglia ${ }^{1}$, \\ Giuliano Meyer ${ }^{1}$, Johannes Fürst ${ }^{2}$, Markus Ritter ${ }^{2}$, Laura Fugazzola ${ }^{3}$, Luca Persani ${ }^{3}$, Patrick Zorowka ${ }^{4}$, \\ Carlo Storelli $^{5}$, Paolo Beck-Peccoz ${ }^{3}$, Guido Bottà ${ }^{1}$ and Markus Paulmichl ${ }^{1,2}$ \\ ${ }^{1}$ Department of Biomolecular Sciences and Biotechnology, Università degli Studi di Milano,Via Celoria 26, I-20133 Milan, Italy, \\ ${ }^{2}$ Department of Physiology and Medical Physics, Medical University of Innsbruck, Fritz-Pregl Strasse 3, A-6020 Innsbruck, Austria, \\ ${ }^{3}$ Institute of Endocrine Sciences, Università degli Studi di Milano, Ospedale Maggiore IRCCS and Istituto Auxologico Italiano IRCCS, Milan, \\ ${ }^{4}$ Department of Otorhinolaryngology, Medical University of Innsbruck and ${ }^{5}$ Department of Biological and Environmental Sciences and Technology, \\ Università degli Studi di Lecce. I-73100 Lecce, Italy
}

(Correspondence should be addressed to M Paulmichl; Email: markus.paulmichl@uibk.ac.at; markus.paulmichl@unimi.it)

\begin{abstract}
Objective: The SLC26A4 protein (pendrin) seems to be involved in the exchange of chloride with other anions, therefore being responsible for iodide organification in the thyroid gland and the conditioning of the endolymphatic fluid in the inner ear. Malfunction of SLC26A4 leads to Pendred syndrome, characterized by mild thyroid dysfunction often associated with goiter and/or prelingual deafness. The precise function of the SLC26A4 protein, however, is still elusive. An open question is still whether the SLC26A4-induced ion exchange mechanism is electrogenic or electroneutral. Recently, it has been shown that human pendrin expressed in monkey cells leads to chloride currents. Methods: We overexpressed the human SLC26A4 isoform in HEK293 Phoenix cells and measured cationic and anionic currents by the patch-clamp technique in whole cell configuration.

Results: Here we show that human pendrin expressed in human cells does not lead to the activation of chloride currents, but, in contrast, leads to an increase of cationic currents.

Conclusion: Our experiments suggest that the SLC26A4-induced chloride transport is electroneutral when expressed in human cellular systems.
\end{abstract}

European Journal of Endocrinology 153 693-699

\section{Introduction}

The SLC26 proteins belong to a family of anion transporters. The characteristics of these transporters vary depending on the subtype of the transporters and/or the tissue in which the transporters are expressed, i.e. the SLC26A4 transporter exchanges chloride by another anion which can be as different as $\mathrm{HCO}_{3}^{-}, \mathrm{OH}^{-}, \mathrm{I}^{-}$or formate $(1-4)$. The different transporters of the SLC26 protein family share the sulfate transporter domain (pfam 00916.11; pfam contains hidden Markov model based profiles of many common protein domains based on multiple sequence alignments (5)), which is most probably involved in the anion exchange mechanism, as well as an STAS domain (pfam 01740.11 (5)), which seems to be involved in the binding of nucleotides and/or the interaction with the cAMP-dependent chloride channel CFTR (cystic fibrosis transmembrane conductance regulator) (6). The latter mechanism was used to explain the rheogenic behaviour of SLC26A3 (also known as down-regulated in adenoma; DRA) and SLC26A6 when expressed in Xenopus laevis oocytes (7). This issue, however seems to be controversial, since in recent studies in which SLC26A3 was expressed in Xenopus laevis oocytes or human embryonic kidney (HEK 293) cells, only an electroneutral chloride transport could be evidenced $(8-10)$. In the pancreas, the bicarbonate secretion at the apical membrane of the duct cells is envisioned to be potential dependent, and again it is unclear whether this is mediated by electrogenic SLC26 transporters, or electroneutral SLC26 transporters functionally linked to CFTR chloride channels (11). It can be concluded from these reports that probably, as for the specificity of the exchanging anions mentioned above, the issue of the transporters electrogenicity also depends on the circumstances (species and cell type) in which the protein is expressed. 
Recently it was shown that SLC26A7 (12) expressed in Xenopus laevis oocytes or HEK 293 cells, as well as SLC26A4 (13) expressed in COS-7 cells, led to electrogenic chloride permeation across the cell membrane. We have shown that SLC26A4 can be functionally expressed in HEK 293 Phoenix cells, leading to an increased chloride uptake.

This increased chloride uptake can be blocked by the chloride channel blocker (5-nitro-2-(3-phenylpropylamino) benzoic acid (NPPB), and is reduced when a mutated SLC26A4 protein isolated from a patient with Pendred syndrome was used for the expression studies (14).

The aim of the present work was to get further insight into the function of pendrin expressed in human cells. We were particularly interested in whether pendrin expressed in HEK 293 Phoenix cells, similarly as described for COS-7 cells (13), is able to lead to chloride currents. Here we show that pendrin expressed in HEK 293 Phoenix cells does not lead to chloride currents. However, the expression of SLC26A4 leads to the stimulation of two kinds of cationic currents when expressed in human cells, namely: (i) an unselective, small amplitude cationic current, and (ii) a selective, voltage-dependent, outwardly rectifying potassium current. The experiments reported here suggest therefore, that the SLC26A4-mediated chloride transport is electroneutral when the expression is performed in human HEK 293 Phoenix cells.

\section{Material and methods \\ Cloning of SLC26A4 cDNA}

Standard procedures were used for DNA preparation, cloning, purification and sequencing. The human wild-type SLC26A4 cDNA was obtained by RT-PCR, using total RNA from normal human thyroid tissue and Taq PLATINUM Pfx DNA polymerase (Invitrogen). The SLC26A4 open reading frame was cloned into pIRES2-EGFP (Clontech). This vector permits both the cDNA of interest (cloned into the multiple cloning site (MCS)) and the enhanced green fluorescence protein (EGFP) coding sequence to be translated from a single bicistronic mRNA, and therefore to produce two separated proteins simultaneously. The EGFP fluorescence (excitation maximum $=488 \mathrm{~nm}$; emission maximum $=509 \mathrm{~nm}$ ) enables us to identify the cells expressing the protein of interest, and therefore to optimize the transfection procedure and to control the transfection efficiency. The whole-cell current measurements were restricted to the cells showing an EGFP fluorescence.

\section{Cell culture and transient transfection}

HEK 293 Phoenix cells were grown in minimum essential Eagle medium (Sigma) supplemented with 10\% foetal bovine serum (Cambrex Bio Science), $2 \mathrm{mM}$ L-glutamine, $100 \mathrm{units} / \mathrm{ml}$ penicillin, $100 \mu \mathrm{g} / \mathrm{ml}$ streptomycin and $1 \mathrm{mM}$ pyruvic acid (sodium salt). The cells were maintained at $37^{\circ} \mathrm{C}$ in a $5 \% \mathrm{CO}_{2}: 95 \%$ air humidified incubator; subcultures were routinely established every second to third day by seeding the cells into Petri dishes (diameter $100 \mathrm{~mm}$ ) after trypsin/EDTA treatment. For patch-clamp, HEK cells were transfected with the pIRES2-EGFP vector coding for wild-type SLC26A4, or with the empty plasmid (negative controls) expressing only the EGFP protein and then seeded on glass coverslips (diameter $10 \mathrm{~mm}$ ).

\section{Whole-cell patch-clamp}

Transfected cells were selected by visualizing EGFPexpressing cells with an inverted fluorescence microscope (Axiovert 135, Zeiss). Single transfected cells were voltage-clamped using the patch-clamp technique previously described $(15,16)$. The resistance of the glass pipettes was 3-8 $\mathrm{M} \Omega$ when filled with the respective solutions (Tables 1 and 2) ; fast exchange of the bath solution was obtained using a perfusion system with a flow rate of $5 \mathrm{ml} / \mathrm{min}$ and a bath volume of $\sim 300 \mu \mathrm{l}$. When chloride in the bath solution was changed, the reference electrode was connected via an agar bridge containing $100 \mathrm{mM} \mathrm{KCl}$. All experiments were carried out at room temperature. For data acquisition, an EPC-9 (HEKA Elektronik, Germany) amplifier was used, controlled by a Macintosh computer running the Pulse (HEKA) program. Access resistance, and fast and slow capacitance were compensated and monitored throughout the recordings. All current measurements were filtered at $2.9 \mathrm{kHz}$ and digitized at $2 \mathrm{kHz}$. For data analysis, the Pulse-Fit (HEKA) and Excel (Microsoft) programs were used. The cells were held at $-60 \mathrm{mV}$ and step pulses were applied of $500 \mathrm{~ms}$ duration from -120 to $100 \mathrm{mV}$ in $20 \mathrm{mV}$ steps. Tail $\mathrm{K}^{+}$currents were recorded after a 30-ms depolarizing pre-pulse to $+60 \mathrm{mV}$ from a holding potential of $-60 \mathrm{mV}$. Membrane potentials were corrected for liquid junction potentials. Where indicated, membrane currents were leak-subtracted, and the compositions of the solutions are given in Tables 1 and 2 .

Table 1 Composition (in $\mathrm{mM}$ ) of the different pipette solutions used as indicated in the text.

\begin{tabular}{lccr}
\hline & \multicolumn{3}{c}{ Pipette } \\
\cline { 2 - 4 } & 1 & 2 & 3 \\
\hline CsCl & 125 & 125 & \\
NMDGCl & & 5 & 140 \\
K-aspartate & 5 & 10 & 5 \\
MgCl $_{2}$ & 10 & 2 & 5 \\
EGTA $_{\text {Mg }}^{2+}$ ATP & 2 & 10 & 5 \\
HEPES & 10 & 20 & \\
Raffinose & 20 & 7.2 & 7.2 \\
pH & 7.2 & & \\
\hline
\end{tabular}


Table 2 Composition (in mM) of the different extracelluar (bath) solutions used as indicated in the text.

\begin{tabular}{|c|c|c|c|c|c|c|c|}
\hline & \multicolumn{7}{|c|}{ Bath } \\
\hline & 1 & 2 & 3 & 4 & 5 & 6 & 7 \\
\hline $\mathrm{NaCl}$ & 125 & & & 140 & 5.4 & & 130 \\
\hline $\mathrm{KCl}$ & & & 125 & 5.4 & 140 & 5.4 & 5.4 \\
\hline NMDG Cl & & 125 & & & & & \\
\hline Na-gluconate & & & & & & 40 & \\
\hline TEACl & & & & & & & 10 \\
\hline $\mathrm{MgCl}_{2}$ & 2.5 & 2.5 & 2.5 & 0.5 & 0.5 & 0.5 & 0.5 \\
\hline $\mathrm{CaCl}_{2}$ & 2.5 & 2.5 & 2.5 & 1.8 & 1.8 & 1.8 & 1.8 \\
\hline HEPES & 10 & 10 & 10 & 5 & 5 & 5 & 5 \\
\hline Mannitol & 50 & 50 & 50 & & & & \\
\hline Glucose & & & & 5 & 5 & 5 & 5 \\
\hline $\mathrm{pH}$ & 7.4 & 7.4 & 7.4 & 7.4 & 7.4 & 7.4 & 7.4 \\
\hline
\end{tabular}

\section{Drugs and chemicals}

All drugs and chemicals used are of pro analysis grade.

\section{Statistical analyses}

Data are expressed as arithmetic means \pm S.E. Statistical analysis was made by the unpaired or, where applicable, paired $t$-test. Statistically significant differences were assumed at $P<0.05$.

\section{Results}

\section{Functional expression of SLC26A4 in HEK 293 Phoenix cells}

Recently we showed that pendrin (SLC26A4), when expressed in HEK 293 Phoenix cells, leads to an increased chloride uptake, which was blocked by the addition of NPPB (14). NPPB is known to block chloride transport (17), and since in a earlier study it was shown that SLC26A4 leads to chloride currents when expressed in COS-7 cells (13), we set out to investigate whether SLC26A4 expressed in human HEK 293 Phoenix cells is able to lead to rheogenic chloride transport effected by selective chloride channels.

In order to monitor the SLC26A4 expression in HEK 293 Phoenix cells, we used an IRES-vector allowing the simultaneous expression of SLC26A4 and the marker protein EGFP, which can be verified by fluorescence. As shown in Fig. 1a, the expression of SLC26A4 in HEK 293 Phoenix cells is able to elicit small but statistically significant currents in the inward direction (range of the holding potentials is between -24 and $-124 \mathrm{mV}$ ) and in the outward direction at $+76 \mathrm{mV}$. At these potentials the SLC26A4-induced currents are significantly higher if compared with control currents measured after the expression of the EGFP marker protein alone. The pipette and extracellular solutions used were composed to measure selective chloride currents (the solutions used are for technical reasons not able to exclude unselective cation currents, however they exclude selective potassium currents (see Tables 1 and 2,
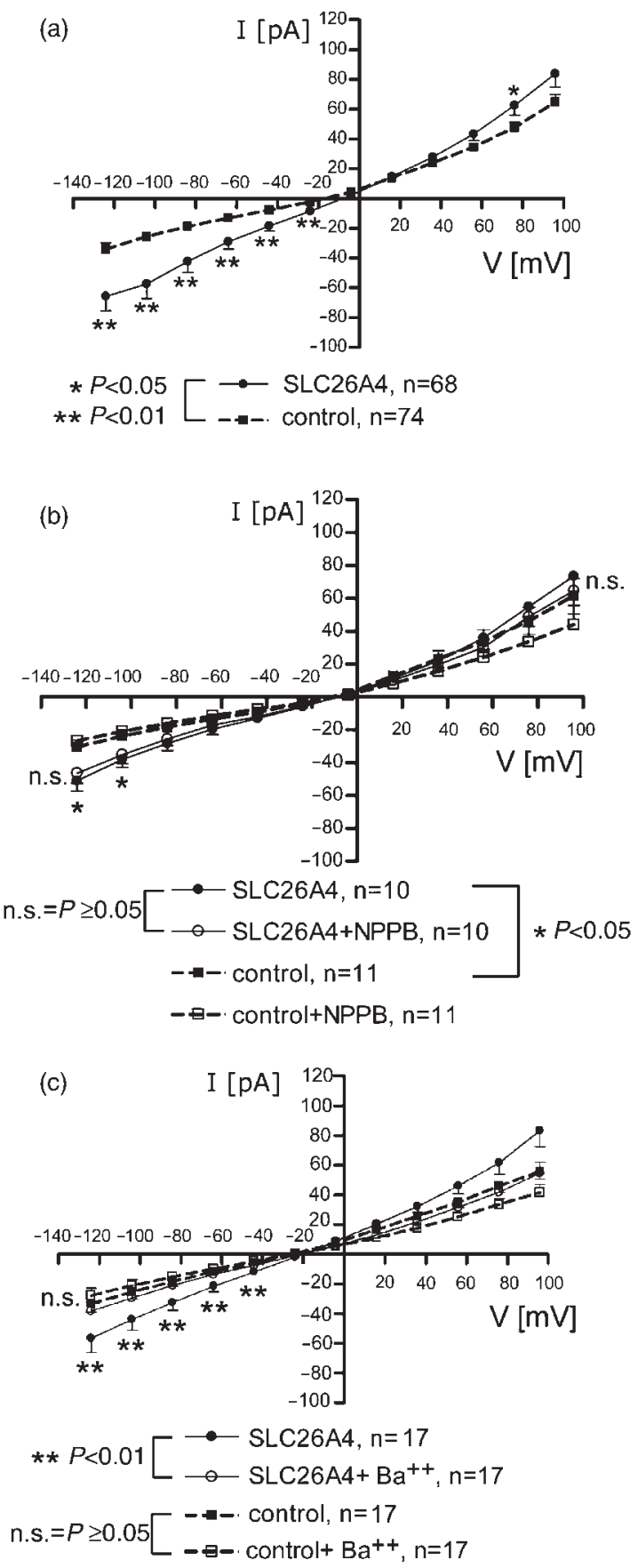

Figure 1 Expression of SLC26A4 in HEK 293 Phoenix cells does not induce chloride currents, but barium-sensitive cationic currents. (a) The currents were measured with and without SLC26A4 expression in the presence of high extracellular and intracellular chloride and in the absence of potassium (bath solution 1 and pipette solution 1; Tables 1 and 2). (b) The SLC26A4-induced currents are not sensitive to NPPB, a substance known to block chloride channels. (c) The SLC26A4-induced currents can be blocked by $1 \mathrm{mM}$ barium. 
pipette solution 1 and bath solution 1 (16, 18-20)). Since the reversal potential of the SLC26A4-induced currents is slightly negative $(-11.4 \pm 2.7 \mathrm{mV}, n=69$, and not significantly different from the control reversal potential at $-18.4 \pm 3.1 \mathrm{mV}, n=74$ ), the measured inward current is most probably the result of an unselective cationic current carried by sodium. That chloride is responsible for the observed inward currents seems not to be very likely, since the calculated reversal potential for chloride (symmetrical chloride concentrations) should be $0 \mathrm{mV}$, and the use of $0.1 \mu \mathrm{M}$ NPPB, a substance used to block a wide range of chloride channels (17), does not reduce the observed inward currents (Fig. 1b). The SLC26A4-induced currents seem therefore to be the result of an unselective cation current. Accordingly, as shown in Fig. 1c, the SLC26A4-enhanced inward current can be blocked by $1 \mathrm{mM}$ barium, and substituting the intracellular (pipette) caesium for $\mathrm{N}$ methly-D-glucamine (NMDG) (pipette solution 2, bath solution 1; Fig. 2a) abolishes the pendrin-induced
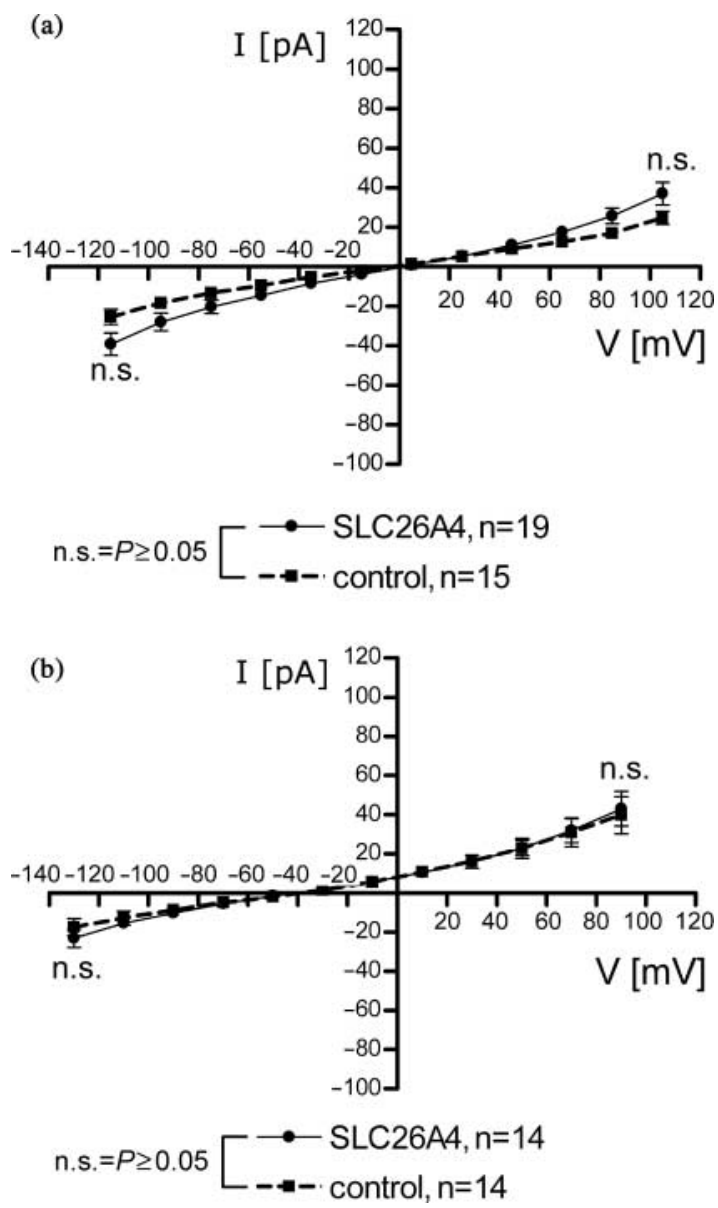

Figure 2 Substituting the permeant cation (caesium in the pipette solution or sodium in the extracellular solution with the non-permeant NMDG abolishes the SLC26A4-induced currents. (a) Intracellular (pipette) caesium is substituted by NMDG (bath solution 1 and pipette solution 2). (b) Extracellular sodium is substituted by NMDG (bath solution 2 and pipette solution 1). currents, as does the substitution of the extracellular cation (sodium) for NMDG (bath solution 2, pipette solution 1; Fig. 2b). Therefore, the SLC26A4-induced currents require diffusible cations, which need to be simultaneously present on either side of the channel pores. In order to test whether the cation (sodium)-carried SLC26A4-induced inward currents can be modified by the presence of potassium in the extracellular fluid we exchanged the extracellular sodium for potassium (bath solution 3, pipette solution 1). As shown in Fig. 3 , at a potential range from -140 to $+60 \mathrm{mV}$, the presence of potassium indeed leads to a modest, but significant, increase of the respective currents. Most important are the findings that: (i) at holding potentials between -40 and $+10 \mathrm{mV}$ the SLC26A4 currents acquire an additional inward component if compared with the SLC26A4 currents in the absence of potassium but in the presence of sodium (bath solution 1, pipette solution 1; Fig. 1); (ii) the reversal potential in the presence of potassium is no longer negative but positive $(+14.3 \pm 4.1 \mathrm{mV}, n=10)$. These findings can only be explained by the appearance of voltage-dependent potassium currents, which are less selective for caesium compared with potassium. Since the experiments carried out so far had not revealed any chloride currents, but clearly showed that SLC26A4 is able to stimulate presumably two different cationic currents, we decided to repeat the experiments by using pipette solutions as well as extracellular solutions that enable the investigation of cationic currents.

\section{Expression of SLC26A4 in HEK 293 Phoenix cells leads to the activation of voltage- dependent potassium currents}

For all further experiments, solutions were used that allow for the characterization of potassium currents

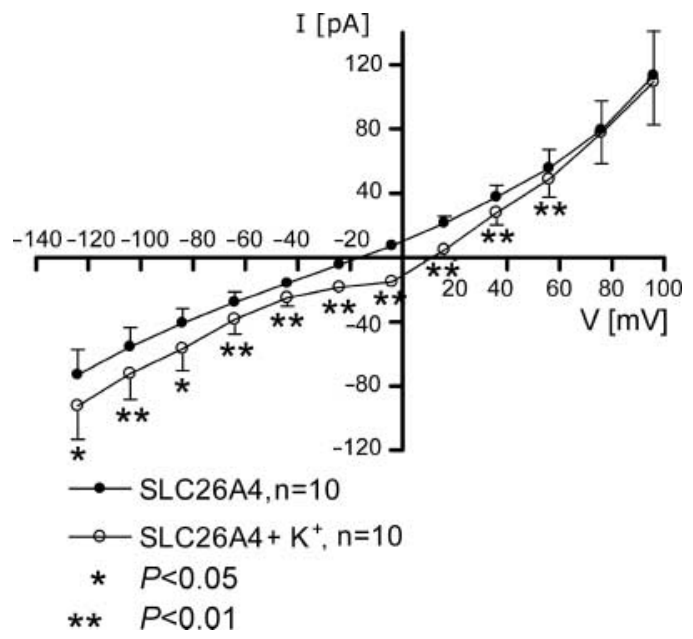

Figure 3 Substituting extracellular sodium with potassium unmasks a voltage-dependent potassium current, activated at $-20 \mathrm{mV}$ in cells expressing SLC26A4 (bath solution 3 and pipette solution 1). 
(Tables 1 and 2) (13). However, these solutions do not allow for discrimination between chloride or potassium currents; this is only a minor problem since the expression of SLC26A4 in human HEK cells does not activate, as reported above, chloride currents.

The omission of caesium (a known blocker for selective potassium channels (21)) and the addition of potassium to the pipette solutions as well as the extracellular solutions leads already under control conditions to voltage-dependent outwardly rectifying currents (bath solution 4, pipette solution 3; Fig. 4). The outwardly rectifying currents were significantly enhanced after the expression of SLC26A4 (Fig. 4). As shown in Fig. 4a, the kinetics of the elicited currents resemble outwardly rectifying and voltage-dependent potassium currents of the $K_{v}$ channel family (22). The currents showed rapid activation and little inactivation at holding potentials above $+40 \mathrm{mV}$, within the $500 \mathrm{~ms}$ tested. The current onset was best fit by a raising exponential of the form

$$
I=I_{\text {peak }}\left[1-\mathrm{e}^{(-t / \tau)}\right]
$$

where $I_{\text {peak }}$ is the peak current and $\tau$ is the time constant of the exponential. The time constants ranged from

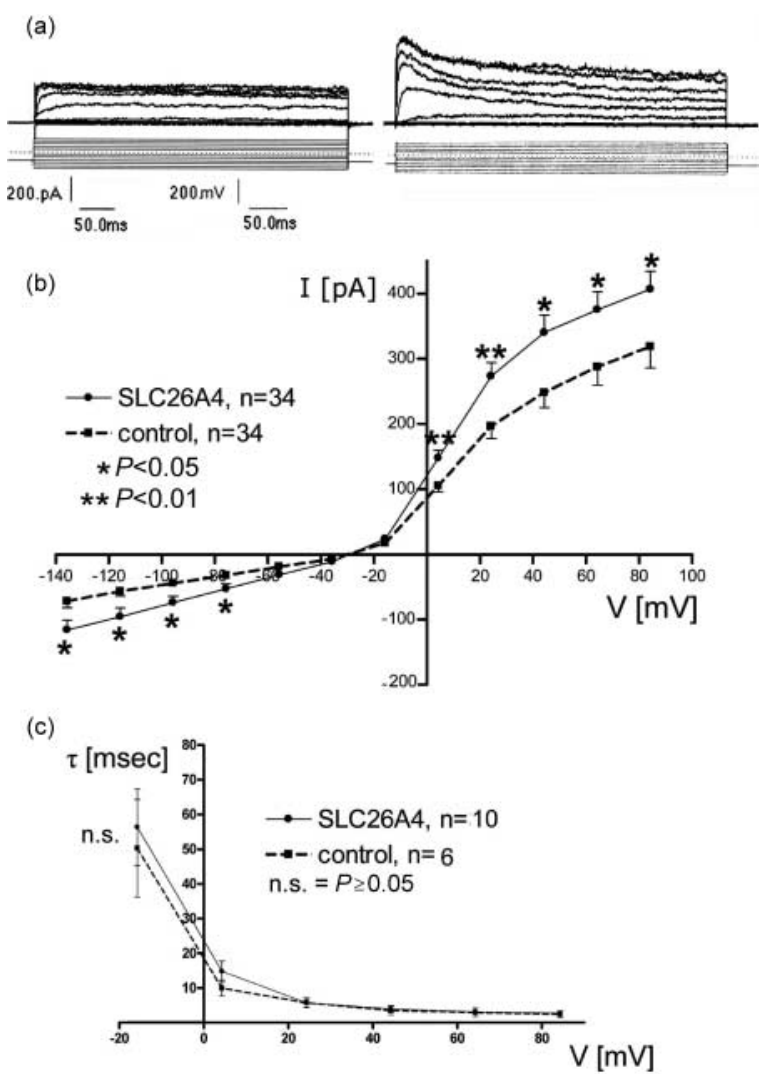

Figure 4 Expression of SLC26A4 in HEK 293 Phoenix cells stimulates voltage-dependent outward-rectifying potassium currents. (a) Two leak-subtracted original tracings (left, under control conditions; right, after the expression of SLC26A4). (b) Summary of the experiments shown in panel a. (c) $\tau$ values of activation for holding potentials ranging from -20 to $+100 \mathrm{mV}$. For these experiments bath solution 4 and pipette solution 3 were used.
$51.3 \pm 11.5 \mathrm{~ms}(n=21)$ at $-15 \mathrm{mV}$ to $2.3 \pm 0.3 \mathrm{~ms}$ $(n=21)$ at $+85 \mathrm{mV}$. Under control conditions, at the same holding potentials, the time constants were $43.6 \pm 7.5 \mathrm{~ms}(n=21)$ at $-15 \mathrm{mV}$ and $2.5 \pm 0.3 \mathrm{~ms}$ $(n=27)$ at $+85 \mathrm{mV}$ respectively, values which are not statistically different from the SLC26A4-induced currents (Fig. 4c).

The voltage-dependent potassium channels can be blocked by tetraethyl ammonium (TEA) (22). As shown in Fig. 5a, the SLC26A4 as well as control currents can be blocked by $10 \mathrm{mM}$ TEA (bath solution 7 , pipette solution 3 ). We consider the remaining currents in the presence of TEA as 'lumped leak currents', and subtracted them from the currents in the presence of SLC26A4 (Fig. 5b). This leads to an $I-V$ plot typical for voltage-dependent outward-rectifying potassium currents, with an activation potential around $-20 \mathrm{mV}$.

Tail currents (Fig. 6a) revealed the potassium selectivity of the SLC26A4-induced currents. As shown in Fig. 6b, the presence of $5.4 \mathrm{mM}$ potassium in
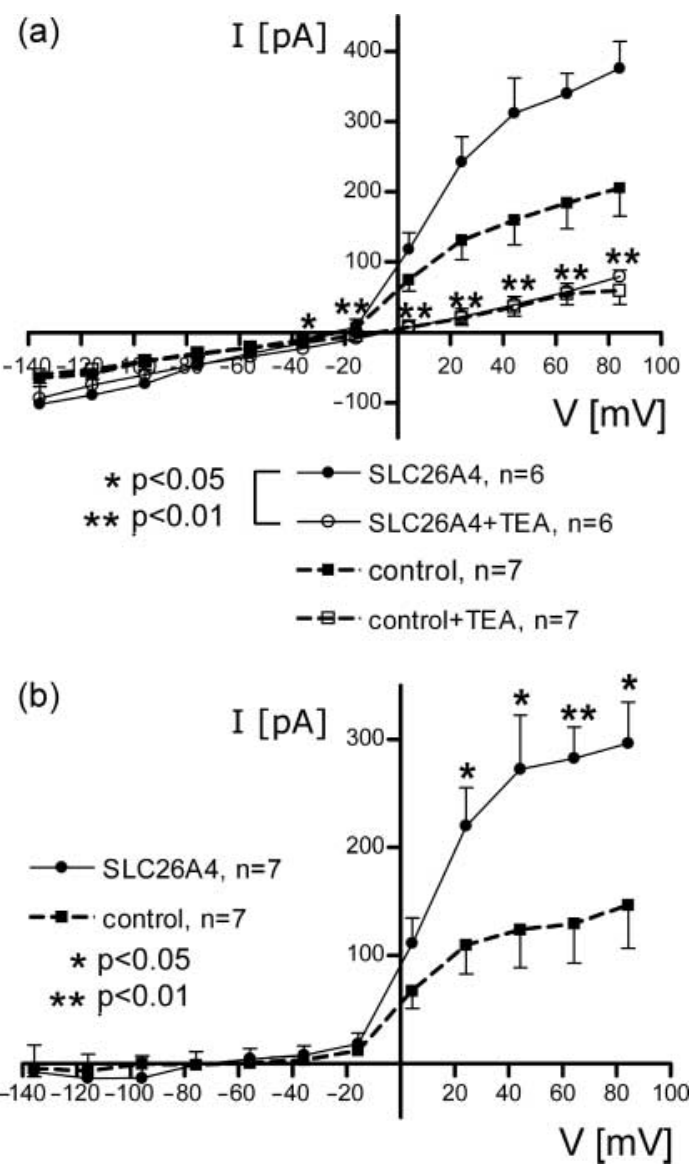

Figure 5 The SLC26A4-stimulated potassium current can be blocked by TEA. (a) Addition of $10 \mathrm{mM}$ TEA leads to inhibition of the pendrin-induced current, as well as the current under control conditions (bath solution 7 and pipette solution 3 ). The remaining current in the presence of $10 \mathrm{mM}$ TEA was subtracted from the control, as well as the SLC26A4-induced current and the result is given in panel $b$. 
(a)
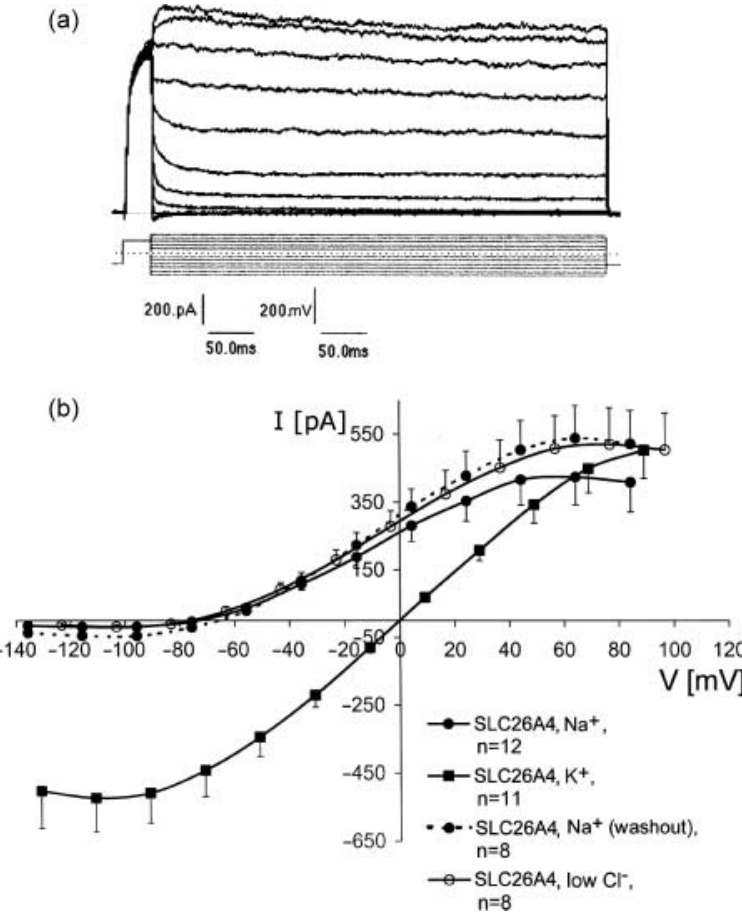

Figure 6 The SLC26A4-induced currents are selective for potassium. (a) Tail reversal potentials were measured by stepping the voltage from -60 to $+60 \mathrm{mV}$ for $30 \mathrm{~ms}$ to activate the voltagedependent currents before returning to the potentials shown in the insert.(b) Summary of the tail currents at the different potentials. The tail $I-V$ plots were first made with high extracellular chloride and low potassium (reversal potential: $-80.1 \pm 4.9 \mathrm{mV}, n=12$; bath solution 4 and pipette solution 3 ), then symmetrical potassium (reversal potential: $-0.2 \pm 0.7 \mathrm{mV}, n=11$; bath solution 5 and pipette solution 3 ), returning to high extracellular chloride (reversa potential: $-64.8 \pm 9.8 \mathrm{mV}, n=8$; bath solution 4 and pipette solution 3 ) and finally reducing the extracellular chloride (reversal potential: $-75.9 \pm 3.2 \mathrm{mV}, n=8$; bath solution 6 and pipette solution 3$)$. All currents are leak subtracted.

the extracellular bath fluid, and $140 \mathrm{mM}$ potassium in the pipette solution leads to a reversal potential of $-80.1 \pm 4.9 \mathrm{mV}(n=12)$; a value close to the calculated $-79.8 \mathrm{mV}$ obtained after transforming the concentrations into the respective activities (bath solution 4, pipette solution 3) (23). Increasing the extracellular potassium concentration to $140 \mathrm{mM}$ leads to a shift to $-0.2 \pm 0.7 \mathrm{mV}(n=11)$, a value not significantly different from the expected $0 \mathrm{mV}$ (bath solution 5, pipette solution 3). However, in contrast, changing the extracellular chloride concentration does not significantly change the measured reversal potential (from $-64.8 \pm 9.8 \mathrm{mV}(n=8)$ to $-75.9 \pm 3.2 \mathrm{mV}(n=8)$; bath solution 6 and pipette solution 3), again indicating that the SLC26A4-induced current is potassium selective, and not a chloride current. The lack of any chloride currents in the presence of SLC26A4 is, however, in contrast to the findings reported by Yoshida et al. (13), who used exactly the same solutions that we used to characterize the potassium currents.

\section{Discussion}

The SLC26A4 protein is mainly expressed in the thyroid gland, inner ear and the kidney, and its malfunction leads to Pendred syndrome (PS; OMIM 274600), a disease often characterized by prelingual deafness and/or goiter $(24,25)$. The detailed function of the SLC26A4 protein is still elusive. In the inner ear SLC26A4 seems to be involved in the conditioning of the endolymphatic fluid $(26,27)$, and in the kidney it is involved in bicarbonate secretion $(28-30)$. In both cases, it is most probable that SLC26A4 is acting as a $\mathrm{Cl}^{-} / \mathrm{HCO}_{3}^{-}$exchanger. In the thyroid gland, however, SLC26A4 is supposed to transport iodide (31). A crucial question for the function of SLC26A4 in the different organ systems, and therefore interpretation of its action in different modular systems (32), is whether or not the transporter itself is electrogenic. Our experiments, in which we expressed the human pendrin in a human cell line, show that the SLC26A4 ion transporter is not, per se, electrogenic; however, the expression of the transporter leads to an increased chloride uptake in these cells (14), which therefore needs to be electroneutral. Our data demonstrate that the expression of SLC26A4 in HEK 293 Phoenix cells leads to the activation of pre-existing unselective cation currents as well as voltage-dependent outwardly rectifying potassium currents. The activation of these currents seems not to be the result of an unspecific perturbation of endoplasmic reticulum function - triggered by the heterologous protein expression (33) - since the activation of the above-mentioned currents by SLC26A4 was compared with control cells, which already express a heterologous protein (i.e. EGFP).

Furthermore, our findings indicate that in the absence of SLC26A4, a reduced activity of outwardly rectifying potassium channels can be measured, which could aggravate the situation described by Wangemann et al. (34) (i.e. the loss of the endocochlear potential in SLC26A4 $4^{-1-}$ mice due to the loss of KCNJ10 potassium channels), and therefore further explains the hearing loss evidenced in those animals.

\section{Acknowledgements}

This work was supported by the Italian Ministry of Instruction, University and Research (MIUR, prot 2003060317), and the Austrian Science Fund (FWF: P13041-med, P15578 and P17119-B05).

\section{References}

1 Scott DA \& Karniski LP. Human pendrin expressed in Хenopus laevis oocytes mediates chloride/formate exchange. American Journal of Physiology. Cell Physiology 2000278 C207-C211.

2 Scott DA, Wang R, Kreman TM, Sheffield VC \& Karniski LP. The Pendred syndrome gene encodes a chloride-iodide transport protein. Nature Genetics 199921 440-443. 
3 Soleimani M, Greeley T, Petrovic S, Wang Z, Amlal H, Kopp P \& Burnham CE. Pendrin: an apical $\mathrm{Cl}^{-} / \mathrm{OH}^{-} / \mathrm{HCO}_{3}^{-}$exchanger in the kidney cortex. American Journal of Physiology. Renal Physiology 2001280 F356-F364.

4 Wolff J. What is the role of pendrin? Thyroid 200515 346-348.

5 Bateman A, Coin L, Durbin R, Finn RD, Hollich V, Griffiths-Jones S, Khanna A, Marshall M, Moxon S, Sonnhammer EL, Studholme DJ, Yeats C \& Eddy SR. The Pfam protein families database. Nucleic Acids Research 200432 D138-D141.

6 Ko SB, Zeng W, Dorwart MR, Luo X, Kim KH, Millen L, Goto H, Naruse S, Soyombo A, Thomas PJ \& Muallem S. Gating of CFTR by the STAS domain of SLC26 transporters. Nature Cell Biolology $20046343-350$.

7 Ko SB, Shcheynikov N, Choi JY, Luo X, Ishibashi K, Thomas PJ, Kim JY, Kim KH, Lee MG, Naruse S \& Muallem S. A molecular mechanism for aberrant CFTR-dependent $\mathrm{HCO}(3)(-)$ transport in cystic fibrosis. EMBO Journal $2002215662-5672$.

8 Melvin JE, Park K, Richardson L, Schultheis PJ \& Shull GE. Mouse down-regulated in adenoma (DRA) is an intestinal $\mathrm{Cl}(-) / \mathrm{HCO}(3)(-)$ exchanger and is up-regulated in colon of mice lacking the $\mathrm{NHE} 3 \mathrm{Na}(+) / \mathrm{H}(+)$ exchanger. Journal of Biological Chemistry $199927422855-22861$.

9 Lamprecht G, Baisch S, Schoenleber E \& Gregor M. Transport properties of the human intestinal anion exchanger DRA (down-regulated in adenoma) in transfected HEK293 cells. Pflugers Archive $2005 \mathbf{4 4 9} 479$-490.

10 Chernova MN, Jiang L, Shmukler BE, Schweinfest CW, Blanco P, Freedman SD, Stewart AK \& Alper SL. Acute regulation of the SLC26A3 congenital chloride diarrhoea anion exchanger (DRA) expressed in Xenopus oocytes. Journal of Physiology 2003 549 3-19.

11 Steward MC, Ishiguro H \& Case RM. Mechanisms of bicarbonate secretion in the pancreatic duct. Annual Review of Physiology $200567377-409$.

12 Kim KH, Shcheynikov N, Wang Y \& Muallem S. SLC26A7 is a Cl-channel regulated by intracellular pH. Journal of Biological Chemistry 2005280 6463-6470.

13 Yoshida A, Hisatome I, Taniguchi S, Sasaki N, Yamamoto Y, Miake J, Fukui H, Shimizu H, Okamura T, Okura T, Igawa O, Shigemasa C, Green ED, Kohn LD \& Suzuki K. Mechanism of iodide/chloride exchange by pendrin. Endocrinology $2004 \mathbf{1 4 5}$ 4301-4308.

14 Bazzini C, Dossena S, Cerutti N, Vezzoli V, Consonni C, Tosco M, Meyer G, Storelli C, Beck-Peccoz P, Botta G \& Paulmichl M. Cloning and functional characterization of human pendrin. Biophysical Journal $2005 \mathbf{8 8} 590$ a.

15 Furst J, Ritter M, Rudzki J, Danzl J, Gschwentner M, Scandella E, Jakab M, Konig M, Oehl B, Lang F, Deetjen P \& Paulmichl M. ICln ion channel splice variants in Caenorhabditis elegans: voltage dependence and interaction with an operon partner protein. Journal of Biological Chemistry 2002277 4435-4445.

16 Gschwentner M, Nagl OU, Wöll E, Schmarda A, Ritter M \& Paulmichl M. Antisense oligonucleotides suppress cell-volumeinduced activation of chloride channels. Pflügers Archive 1995 $430464-470$.

17 Wangemann P, Wittner M, Di Stefano A, Englert HC, Lang HJ, Schlatter E \& Greger R. Cl(-)-channel blockers in the thick ascending limb of the loop of Henle. Structure activity relationship. Pflugers Archive $1986 \mathbf{4 0 7}$ (Suppl 2) S128-S141.

18 Gschwentner M, Susanna A, Wöll E, Ritter M, Nagl UO, Schmarda A, Laich A, Pinggera GM, Ellemunter H, Huemer H, Deetjen P \& Paulmichl M. Antiviral drugs from the nucleoside analog family block volume-activated chloride channels. Molecular Medicine 19951 407-417.

19 Gschwentner M, Fürst J, Schmarda A, Bazzini C, Wöll E, Ritter M, Dienstl A, Scandella E, Oehl B, Hohlrieder M \& Paulmichl M. Is ICln a swelling dependent chloride channel? In Cell Volume
Regulation: The Molecular Mechanism and Volume Sensing Machinery pp 131-139. Ed Yokada. Amsterdam: Elsevier Science, 1998.

20 Furst J, Gschwentner M, Ritter M, Botta G, Jakab M, Mayer M, Garavaglia L, Bazzini C, Rodighiero S, Meyer G, Eichmuller S, Woll E \& Paulmichl M. Molecular and functional aspects of anionic channels activated during regulatory volume decrease in mammalian cells. Pflugers Archive 2002444 1-25.

21 Hille B. Ionic Channels of Excitable Membranes. Sunderland, Massachusetts: Sinauer Associates, Inc., 1992.

22 Paulmichl M, Nasmith P, Hellmiss R, Reed K, Boyle WA, Nerbonne JM, Peralta EG \& Clapham DE. Cloning and expression of a rat cardiac delayed rectifier potassium channel. PNAS 1991 $887892-7895$.

23 Sakmann B \& Neher E. Single-Channel Recording. New York: Plenum Press, 1995.

24 Everett LA \& Green ED. A family of mammalian anion transporters and their involvement in human genetic diseases. Human Molecular Genetics 19998 1883-1891.

25 Wilcox ER, Everett LA, Li XC, Lalwani AK \& Green ED. The PDS gene Pendred syndrome and non-syndromic deafness DFNB4. Advances in Otorhinolaryngology 200056 145-151.

26 Royaux IE, Belyantseva IA, Wu T, Kachar B, Everett LA, Marcus DC \& Green ED. Localization and functional studies of pendrin in the mouse inner ear provide insight about the etiology of deafness in pendred syndrome. Journal of the Association of Research in Otolaryngology 20034 394-404.

27 Dou H, Xu J, Wang Z, Smith AN, Soleimani M, Karet FE, Greinwald JH Jr \& Choo D. Co-expression of pendrin, vacuolar $\mathrm{H}+$-ATPase alpha4-subunit and carbonic anhydrase II in epithelial cells of the murine endolymphatic sac. Journal of Histochemistry and Cytochemistry 200452 1377-1384.

28 Kim YH, Kwon TH, Frische S, Kim J, Tisher CC, Madsen KM \& Nielsen S. Immunocytochemical localization of pendrin in intercalated cell subtypes in rat and mouse kidney. American Journal of Physiology. Renal Physiology 2002283 F744-F754.

29 Wall SM, Hassell KA, Royaux IE, Green ED, Chang JY, Shipley GL \& Verlander JW. Localization of pendrin in mouse kidney. American Journal of Physiology. Renal Physiology 2003 284 F229-F241.

30 Royaux IE, Wall SM, Karniski LP, Everett LA, Suzuki K, Knepper MA \& Green ED. Pendrin, encoded by the Pendred syndrome gene, resides in the apical region of renal intercalated cells and mediates bicarbonate secretion. PNAS $2001 \mathbf{9 8}$ 4221-4226.

31 Royaux IE, Suzuki K, Mori A, Katoh R, Everett LA, Kohn LD \& Green ED. Pendrin, the protein encoded by the Pendred syndrome gene (PDS), is an apical porter of iodide in the thyroid and is regulated by thyroglobulin in FRTL-5 cells. Endocrinology 2000 141 839-845.

32 Guimera R \& Nunes Amaral LA. Functional cartography of complex metabolic networks. Nature 2005433 895-900.

33 Shepshelovich J, Goldstein-Magal L, Globerson A, Yen PM, Rotman-Pikielny P \& Hirschberg K. Protein synthesis inhibitors and the chemical chaperone TMAO reverse endoplasmic reticulum perturbation induced by overexpression of the iodide transporter pendrin. Journal of Cell Science 2005118 1577-1586.

34 Wangemann P, Itza EM, Albrecht B, Wu T, Jabba SV, Maganti RJ, Lee JH, Everett LA, Wall SM, Royaux IE, Green ED \& Marcus DC. Loss of KCNJ10 protein expression abolishes endocochlear potential and causes deafness in Pendred syndrome mouse model. BMC Med 2004230.

Received 24 May 2005

Accepted 4 August 2005 